\title{
HISTORIA POLÍTICA DE CHILE, 1810-2010. TOMO I: PRÁCTICAS POLÍTICAS
}

Iván Jacksic y Juan Luis Ossa (eds.), Historia política de Chile, 1810-2010. Tomo I: Prácticas políticas, Santiago, Fondo de Cultura Económica, 2017, 508 pp.

En palabras de Iván Jacksic, los dos siglos de vida republicana de Chile han suscitado un interés renovado por el estudio historiográfico de la política en tanto eje aglutinador de la nación, árbitro de las diferencias y generador de proyectos de largo alcance. El primer tomo de Historia política de Chile, 1810-2010, aborda dicho interés con una visión desde y para la acción, «considerando a los actores como agentes dinámicos cuya historicidad debe ser explicada y no dada por supuesta». Centrándose en las prácticas que diversos actores y colectividades desplegaron en este período, el volumen reúne 14 trabajos de académicos y especialistas que, de modo introductorio, entregan una visión panorámica de los conflictos, espacios y disputas en que la acción de estos actores y grupos ha tenido lugar a lo largo de la historia chilena en los siglos XIX y XX.

Los trabajos que constituyen este libro exploran la vida política desde la óptica de las prácticas concretas. Por lo mismo, la preocupación principal son las razones, motivaciones y necesidades que llevaron a distintos actores, en distintos momentos y espacios, a organizarse colectivamente y desplegar su acción con el objetivo de disputar o, al menos, incidir en el acceso y ejercicio del poder, para tratar de dar solución a sus preocupaciones tanto de orden material como político. El volumen gira en torno a cuatro grandes problemas historiográficos y ejes articuladores: revolución y guerra, asociacionismo, participación social en la disputa por el poder, y el binomio democracia y dictadura.

En los capítulos 1 y 2, «Revolución y construcción republicana en Chile, 1810-1851» y «Las guerras civiles en Chile», de los historiadores Juan Luis Ossa y Joaquín Fernández respectivamente, se abordan coyunturas de tensión y enfrentamiento durante el siglo XIX, centrándose en el fenómeno de la guerra civil como categoría analítica central. En su capítulo, Juan Luis Ossa estudia el proceso de independencia y construcción estatal en Chile, sosteniendo que se trató de una guerra civil de carácter revolucionario, pues transformó estructuralmente el sistema político de la hasta entonces Capitanía General. Lo novedoso del trabajo de Ossa recae en entender el proceso de independencia como un conflicto en que diversos sectores de una misma sociedad entraron en disputa por el de- 
venir histórico de lo que posteriormente sería conocido como Chile, siendo este el componente "civil” más allá del binomio españoles/criollos. Ossa discute la visión teleológica del proceso independentista, planteando que éste no fue un proceso rupturista en su totalidad, pues existieron proyectos con tintes monárquico-constitucionalistas de forma paralela al proyecto rupturista frente al control de la metrópoli. En la misma línea de la disputa política, Joaquín Fernández estudia las guerras civiles en Chile, planteándolas como un medio de cuestionamiento de la legitimidad de los procesos electorales, al mismo tiempo que de invocación de principios constitucionalistas de carácter liberal por parte de los grupos excluidos del gobierno. Los episodios de enfrentamiento se entienden como la continuación de la disputa entre varios proyectos en el marco de la construcción estatal en Chile. Finalmente, en el capítulo 3, «Los militares y la política en Chile, 1810-2015», Augusto Varas analiza el rol de los militares en la política chilena y sus vaivenes entre la intervención directa, el aislamiento corporativo de la escena y la doctrina de seguridad nacional. El argumento central del autor es que estos vaivenes en el accionar militar se deben a la incapacidad de ejercer un control democrático por parte del gobierno sobre el ejército, además de la ambigüedad doctrinaria de una institución que se ha desplazado desde el nacionalismo independentista, pasando por la autonomía integracionista hasta el profesionalismo democrático.

El asociacionismo es abordado en los capítulos 4, 5, 6 y 7. En «El asociacionismo político en Chile. Trayectorias de organización, reivindicación y resistencia en el Chile republicano», Andrés Baeza estudia las prácticas de asociación colectiva de sujetos con objetivos comunes, planteando que el asociacionismo fue un mecanismo fundamental de acción y transformación política en la historia republicana del país, con la particularidad de que, en general, dicha acción buscó una mayor involucración del Estado en la solución a los problemas materiales y colectivos de estos grupos asociados, con una clara intención de incidir en la promulgación de leyes. María Elisa Fernández, por su parte, estudia la conformación de partidos políticos, analizando la trayectoria de las principales agrupaciones partidarias en los siglos XIX y XX. El argumento central es que la creación de partidos responde a situaciones que involucran ansias de poder, necesidad de resolver problemas concretos y de representar a los grupos sociales. Para eso, Fernández recorre los principales problemas y tensiones en los dos siglos de vida republicana, y las disputas en torno a esas conflictividades por parte de los conglomerados.

Eduardo Posada Carbó complementa el estudio de los partidos políticos desde la perspectiva electoral, analizando la participación en los procesos electivos no solo en términos del número de votos, sino también la diversidad de actividades y prácticas desplegadas por los distintos grupos, como banquetes, encuentros, fiestas y giras que formaban parte del proceso electoral y del repertorio de prácticas para acarrear votantes. Concluye el autor que estas actividades, junto con la expansión del sufragio, permitieron una progresiva democratización de los procesos electorales en Chile. Carla Rivera, por su parte, complementa la obra de Posada analizando el rol de la prensa a lo largo del período de estudio, planteando que esta, en tanto órgano de difusión de información, sirvió como herramienta para determinados sectores de la sociedad para transmitir 
representaciones e informaciones desde una posición de enunciación particular y subjetiva.

El rol de las mujeres en la conformación de la república forma parte tanto del problema del asociacionismo como de la participación social en la política. María Rosaria Stabili recorre la historia de la organización femenina en estos años, viendo cómo las agrupaciones de mujeres se manifestaron en torno a conflictos y disputas propias de su época. La autora discute el binomio esfera pública/privada para explicar la praxis femenina, planteando que las mujeres, en distintos momentos históricos, tuvieron participación protagónica en la esfera pública de la nación, con capacidad de influencia directa en la promulgación de leyes. Ejemplos de lo dicho son las revistas de prensa femenina y la organización de mujeres en el MEMCh. En esta misma línea, Elizabeth Quay y María Soledad Zárate, en su capítulo «Clases medias en Chile: Estado, género y prácticas políticas, 1920-1970», analiza cómo las prácticas de este sector heterogéneo de la sociedad demuestran un compromiso con la modernización del Estado, la democracia, la reforma social y el desarrollo, en estrecho vínculo con la expansión de los profesionales, de los empleados públicos y la inclusión femenina en la esfera política, en un período dominado por los discursos de clase de los trabajadores y las élites gobernantes. En el capítulo 10, titulado «Manipulando el "alma del pueblo": Cultura y prácticas políticas en el Chile contemporáneo», Patrick Barr-Melej aborda el estrecho vínculo entre cultura y política, viendo cómo las esferas y expresiones culturales fueron objeto e instrumento de disputa por parte de determinados grupos de la sociedad chilena, y que a la larga terminó en la incorporación de los artistas a la vida política de la nación. Esta instrumentalización de la cultura significó la apropiación de determinados estilos artísticos como portavoces de las tendencias que representaban, como lo es el caso de la Nueva Canción y su estrecho vínculo con la izquierda chilena desde la década de 1960.

En el capítulo «Movimientos obreros y movimientos sociales populares en Chile», Luis Thielemann estudia el recorrido de la movilización popular en Chile desde el siglo XIX hasta principios del siglo XXI, analizando los vínculos y contradicciones entre las distintas expresiones del mundo popular en el período de estudio. El autor plantea que estas diferencias fueron mediadas por ideologías diversas así como por la capacidad orgánica de ser útiles a la realización de los intereses de clase, entendiendo que lo común de los sectores populares era el lugar que ocupaban en la cadena de producción. El recorrido de estas expresiones en varios momentos del desarrollo capitalista en Chile, encuentra su punto cúlmine en el golpe de 1973, cuando se destruye el proyecto popular unitario de la Unidad Popular y se da inicio a la represión y desarticulación de estos sectores por parte de la dictadura militar del general Pinochet. Por último, en «Sociedad rural y política nacional en Chile central», Claudio Robles analiza el campo chileno del valle central, sosteniendo el argumento de que campesinos y terratenientes emplearon un dinámico repertorio de prácticas políticas a lo largo de los siglos de vida independiente de Chile, destacando la complejidad de un espacio que ha sido caracterizado, supuestamente, por una tardía emergencia del conflicto social. Así, el autor estudia la praxis del campesinado antes de la Reforma Agraria, centrándose en los métodos de resistencia cotidiana como forma de rei- 
vindicación campesina durante el siglo XIX y en la conformación del incipiente movimiento campesino a principios del siglo XX. Culmina su trabajo observando el recorrido del campesinado como sujeto histórico hasta la Reforma Agraria, período de mayor actividad y movilización en el campo producto de la politización y sindicalización campesina.

El cuarto problema historiográfico abordado en el libro es la tensión entre democracia y dictadura. Sobre este tema, los capítulos 11 y 12, titulados «Democracia y dictadura en el Chile republicano. Prácticas, debates y conflicto político», de Marcelo Casals, y «La violencia política en Chile: contextos y prácticas desde 1810», de Brian Loveman y Elizabeth Lira, plantean enfoques novedosos respecto a la tensión entre democracia, violencia y dictadura en una sociedad republicana. Casals trabaja esta tensión desde una perspectiva que sitúa el término 'democracia' en una constante disputa, y que ha servido también como justificación para ciertos proyectos dictatoriales bajo la premisa de recuperar la democracia y el orden requerido para su funcionamiento. El argumento central es que la matriz liberal del Estado impuso límites a la larga infranqueables para las prácticas y los debates sobre la democracia - liberal - y, sobre todo, para la dictadura. Por ende, no hubo espacios para posiciones declaradamente antidemocráticas en la vida republicana de Chile, sino que las experiencias dictatoriales han requerido moverse dentro de esta matriz liberal en donde la defensa de la democracia y las libertades se alzaron como justificación para la concentración dictatorial del poder. Como complemento a lo planteado por Casals, Loveman y Lira analizan la violencia política a lo largo del período y las razones y motivaciones que llevaron a su empleo. Se sostiene que la violencia, ejercida tanto desde el Estado y sus agentes como por actores de la sociedad civil, ha jugado un papel determinante en la formación del Estado chileno, en su desarrollo, en sus procesos electorales y en la formulación de leyes y decretos, así como en la resistencia por parte de partidos y grupos sociales. Las autoras hacen un recorrido por los distintos tipos de violencia tanto desde el Estado como en resistencia a su actuar, y concluyen que, si bien ésta no ha caracterizado al país, sí ha constituido un repertorio de mecanismos por parte de varios grupos, para intervenir políticamente en el devenir de la nación.

En suma, el primer tomo de Historia política de Chile constituye un trabajo panorámico e introductorio a las distintas manifestaciones de praxis política a lo largo de la vida republicana en Chile. El principal aporte de los trabajos agrupados en el libro es que permite discutir una visión, a menudo consensuada en la historiografía nacional, de la supuesta "excepcionalidad chilena" en el proceso de construcción estatal, una visión sesgada que ha hecho vista gorda a los distintos momentos de conflicto y tensiones en la vida republicana del país. El estudio de estas prácticas, ya sea militares o de organización social, como también de su contexto histórico, permite comprender las posturas, encuentros y desencuentros que han existido a lo largo de dos siglos de vida independiente en Chile, y que a la larga han determinado el desarrollo histórico del Estado y la sociedad chilena hasta nuestros días.

Matías Moreno Durán Pontificia Universidad Católica de Chile 